\title{
The spatial distribution of illegal hunting of terrestrial mammals in Sub-Saharan Africa: a systematic map
}

\author{
Isla Duporge ${ }^{1 *} \mathbb{D}$, Timothy Hodgetts ${ }^{1}$, Tiejun Wang ${ }^{2}$ and David W. Macdonald ${ }^{1}$
}

\begin{abstract}
Background: There is a rich body of literature addressing the topic of illegal hunting of wild terrestrial mammals. Studies on this topic have risen over the last decade as species are under increasing risk from anthropogenic threats. Sub-Saharan Africa contains the highest number of terrestrial mammals listed as vulnerable, endangered or critically endangered. However, the spatial distribution of illegal hunting incidences is not well documented. To address this knowledge gap, the systematic map presented here aims to answer three research questions: (1) What data are available on the spatial distribution of illegal hunting of terrestrial mammals in Sub-Saharan Africa in relation to environmental and anthropogenic correlates i.e. proximity to roads, water bodies, human settlement areas, different land tenure arrangements and anti-poaching ranger patrol bases? (2) Which research methodologies have primarily been used to collect quantitative data and how comparable are these data? (3) Is there a bias in the research body toward particular taxa and geographical areas?
\end{abstract}

Methods: Systematic searches were carried out across eight bibliographic databases; articles were screened against pre-defined criteria. Only wild terrestrial mammals listed as vulnerable, endangered or critically endangered by the International Union for Conservation of Nature (IUCN) whose geographical range falls in Sub-Saharan Africa and whose threat assessment includes hunting and trapping were included. To meet our criteria, studies were required to include quantitative, spatially explicit data. In total 14,325 articles were screened at the level of title and abstract and 206 articles were screened at full text. Forty-seven of these articles met the pre-defined inclusion criteria.

Results: Spatially explicit data on illegal hunting are available for 29 species in 19 of the 46 countries that constitute Sub-Saharan Africa. Data collection methods include GPS and radio tracking, bushmeat household and market surveys, data from anti-poaching patrols, hunting follows and first-hand monitoring of poaching signs via line transects, audio and aerial surveys. Most studies have been conducted in a single protected area exploring spatial patterns in illegal hunting with respect to the surrounding land. Several spatial biases were detected.

Conclusions: There is a considerable lack of systematically collected quantitative data showing the distribution of illegal hunting incidences and few comparative studies between different tenure areas. The majority of studies have been conducted in a single protected area looking at hunting on a gradient to surrounding village land. From the studies included in the map it is evident there are spatial patterns regarding environmental and anthropogenic correlates. For example, hunting increases in proximity to transport networks (roads and railway lines), to water sources, to

\footnotetext{
*Correspondence: Isla.duporge@zoo.ox.ac.uk

${ }^{1}$ Wildlife Conservation Research Unit, Department of Zoology, University

of Oxford, Recanati-Kaplan Centre, Tubney, Abingdon OX13 5QL, UK

Full list of author information is available at the end of the article

This article is related to https://doi.org/10.1186/s13750-018-0139-x.
}

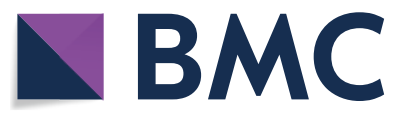

(c) The Author(s) 2020. This article is licensed under a Creative Commons Attribution 4.0 International License, which permits use, sharing, adaptation, distribution and reproduction in any medium or format, as long as you give appropriate credit to the original author(s) and the source, provide a link to the Creative Commons licence, and indicate if changes were made. The images or other third party material in this article are included in the article's Creative Commons licence, unless indicated otherwise in a credit line to the material. If material is not included in the article's Creative Commons licence and your intended use is not permitted by statutory regulation or exceeds the permitted use, you will need to obtain permission directly from the copyright holder. To view a copy of this licence, visit http://creativeco mmons.org/licenses/by/4.0/. The Creative Commons Public Domain Dedication waiver (http://creativecommons.org/publicdomain/ zero/1.0/) applies to the data made available in this article, unless otherwise stated in a credit line to the data. 
the border of protected areas and to village land. The influence of these spatial features could be further investigated through meta-analysis. There is a diverse range of methods in use to collect data on illicit hunting mainly drawing on pre-existing law enforcement data or researcher led surveys detecting signs of poaching. There are few longitudinal studies with most studies representing just one season of data collection and there is a geographical research bias toward Tanzania and a lack of studies in Central Africa.

Keywords: Poaching, Snaring, Bushmeat, Wildmeat, Wildlife, Trapping, Conservation, Biodiversity, Anthropocene

\section{Background}

We are now in the geological epoch of the Anthropocene, where human activity is the dominant force of change on earth and the planet is undergoing a sixth mass extinction [1]. Rising human populations and industrialisation is causing habitat fragmentation reducing habitat connectivity for many species [2,3]. Restricted home ranges mean species have greater contact with human settlements resulting in increased retaliatory killing. This is particularly noticeable in the case of elephants who have less foraging space and resort to crop-raiding [4-6] and carnivores who predate on livestock and, occasionally, humans [7-9]. In addition to habitat fragmentation, one of the primary drivers of species decline is an increase in illegal hunting used as a source of subsistence and income driven largely by poverty and limited employment opportunities [10]. Due to these converging pressures, an increasing number of terrestrial mammals have been uplisted into the endangered categories by the International Union of Conservation for Nature (IUCN) - the leading international authority on species population monitoring [8]. Sub-Saharan Africa is the region that contains the highest number of terrestrial mammals listed as vulnerable, endangered or critically endangered by the IUCN, and is the focus region of this study.

The landscape of anthropogenic risk is shifting as land tenure and land ownership arrangements change. While tenure arrangements (i.e. who holds ownership rights) are different to how land is managed and administered, ownership has a significant impact on the potential land uses of an area. Domestic speculation and erosion of tribal controls and mores are significantly altering local land ownership arrangements $[11,12]$. Globally, increasing liberalisation of land markets is leading to the rising privatisation of land. This trend is particularly noticeable in Sub-Saharan Africa, where $60 \%$ of the world's uncultivated arable land is found-acquiring this land is highly attractive to foreign agribusiness investors, particularly as large tracts of land are meeting less than $25 \%$ of potential yield [13]. In Sub-Saharan Africa, over $80 \%$ of land outside of protected areas is under a customary land tenure arrangement. While there is a rich literature on the impact foreign land acquisition has on local communities, there are few studies on the way the shifting land ownership mosaic is affecting wildlife [14-16]. Generating a better understanding of the spatial distribution of illegal hunting incidences can guide conservation practitioners to identify locations that would be most beneficial to position wildlife ranger posts and concentrate anti-poaching activities.

Analysing spatial variation in poaching incidences is of increasing relevance as an increasing number of tools using Artificial Intelligence (AI) and Machine Learning are developed to predict where illegal hunting incidents will take place [17]. Analysing patrol data is complex because of biases in the way data are collected i.e. rangers more frequently patrol around posts and locations where carcasses were previously detected. Improved analytical insight is now possible due to improved modelling capabilities, which work to account for collection bias [18], however, outputs will always be highly dependent on the quality of the input data. One model using data from the Serengeti, Tanzania assessed the cost and benefit of different poaching hotspots in the landscape. The model made high accuracy predictions when compared with areas where animals were subsequently snared [19]. Another predictive spatiotemporal model applied in Uganda evaluated against 5 months of field data was able to successfully predict poaching locations [18].

Generating an overview of the spatial distribution of illegal hunting incidences in Sub-Saharan Africa can guide conservation efforts. The map outlines the research methodologies that have been used to collect illegal poaching data.

The questions this systematic map responds to were identified as a knowledge gap during several meetings at the Wildlife Conservation Research Unit, University of Oxford. It has been requested that the findings from this map be presented at the Fourteenth United Nations Congress on Crime Prevention and Criminal Justice in Kyoto, Japan at an event considering "Rethinking the 'boundary-arrangement' for an evidence-based approach in addressing wildlife and forest crime".

\section{The objective of the review}

The objective is to collate the spatially explicit evidence on the illegal hunting of wild terrestrial mammals of 
conservation concern in Sub-Saharan Africa. The map answers three research questions:

(1) What data are available on the spatial distribution of illegal hunting of terrestrial mammals in Sub-Saharan Africa in relation to environmental and anthropogenic correlates i.e. proximity to roads, water bodies, human settlement areas, different land tenure arrangements and anti-poaching ranger patrol bases? (2) Which research methodologies have primarily been used to collect quantitative data and how comparable are these data? (3) Is there a bias in the research body toward particular taxa and geographical areas?

The map analyses comparable static geographical information across various locations. It is recognised that there are important sociological drivers of illegal hunting i.e. education level, wildmeat value chains and alternative sources of protein, among others, however, these are not the focus of the study.

To understand the spatial distribution of illegal hunting of terrestrial mammals in Sub-Saharan Africa, the main components of the question are as follows:

- Population: Wild terrestrial mammals listed as vulnerable, endangered or critically endangered by the IUCN for whom the threat assessment includes hunting and trapping and whose geographical range falls in Sub-Saharan Africa (listed in Additional file 1).

- Exposure: Location of illegal hunt

- Comparator: Contrasting proximity of illegal hunt to the following geographical variables-water bodies, transport networks, anti-poaching range patrol bases, human settlement areas.

- Outcomes: Spatial data on the geographic distribution of illegal hunting.

\section{Methods}

The protocol of this review was published in November 2018 [20]. The protocol largely focuses on how tenure influences illegal hunting, however, once the review was underway the focus shifted toward the spatial distribution of illegal hunting in relation to numerous geographic variables e.g. proximity to water, transport networks, ranger patrol posts. This shift was necessary because it became apparent that the majority of studies analyse illegal hunting in one protected area looking at distribution in relation to surrounding village land. Many articles that analyse illegal hunting do not go into detail on what constitutes illegality, cross-border trafficking chains complicate legality as legal status changes across borders. It was decided that if the study referred to hunting as illegal it would be included.

\section{Search for articles}

We searched the eight academic databases outlined in the protocol; the review team validated the search terms across databases testing alternative search strings. The terms were tested against four known articles; these articles were selected as the benchmark articles as they reflect a selection of methodological approaches relevant to the systematic map (Additional file 2). The search strings were developed in the Web of Science Core Collection. The search string was designed with assistance from information specialists at both the Oxford Bodleian Library and the University of Exeter to ensure that variations of relevant terms were included, and the Boolean logic applied was consistent across databases. All searches were conducted between December 2018 and January 2019.

All results were exported into EndNote X8 and the searches from Web of Science Core Collection and SCOPUS were used as the reference set for de-duplication. The search terms and results per database are recorded in Additional file 2. Access to all databases was provided by the University of Oxford Bodleian Library Institutional License. The search was restricted to studies conducted in the last three decades, since 1990; this cut off was chosen so the results have contemporary relevance. Only articles published in English were screened and the search string was applied under Topic subject covering Title, Abstract, and Keywords.

\section{Search string}

$\mathrm{TS}=\left(\left(\mathrm{mammal}^{*}\right.\right.$ OR fauna OR wildlife OR animal* $)$ AND tenure OR land NEAR/2 (ownership OR right* OR holding* OR title OR administration OR management OR tenan* OR deed* OR pastoral OR private OR commun* OR customary OR state) OR "natural resource" NEAR/2 (ownership OR right* OR management OR regim* OR private OR commun* OR customary OR state) OR "property regime" OR area NEAR/2 (communal OR protected OR communit* OR freehold OR "free leasehold" OR "Wildlife Management") OR ownership NEAR/2 (pastoral OR private OR commun* OR customary OR state) AND (hunt* OR poach* OR bushmeat OR trap* OR snar* OR vulnerabl* OR endangered OR threatened OR risk OR "conservation dependent" OR extinct")).

The search terms were kept as consistent as possible and all searches were recorded so the searches can be easily repeated in the future.

All the following databases were searched using the subscription of the University of Oxford:

- Agricola [http://agricola.nal.usda.gov].

- AGRIS [http://agris.fao.org/]. 
- BIOSIS: Biological Abstracts (Accessed via Web of Science-BIOSIS Citation Index-1969-Present).

- CAB Abstracts (Accessed via Ovid).

- PAIS Index (Accessed via ProQuest).

- SCOPUS (http://www.scopus.com).

- Web of Science Core Collection: citation indexes listed in Additional file 2.

- Zoological record (Accessed via Ovid).

\section{Deviations from the protocol}

To ensure the expanded focus was encapsulated in the search strategy the search terms were rerun removing keywords relating to tenure. The resulting articles which met the inclusion criteria remained the same. The population criteria were amended to include studies focused on multiple species where it is stated hunting is illegal, but the species hunted is not specified. It was necessary to interpret this criterion liberally as a large number of studies focused on the illegal hunting of multiple species using the umbrella term 'bushmeat' - referring broadly to mammals killed for subsistence.

\section{Article screening}

\section{Screening process}

The inclusion criteria were applied during the title and abstract screening and all articles were double screened by two authors. Once $20 \%$ of articles had been screened, the corresponding authors met to check for consistency between the screening choices. All disagreements during screening were discussed and reconciled between the team of three reviewers. Cohen's kappa statistic was calculated after double screening all articles $(12,403)$ by three authors, resulting in 0.929 and 0.884 (Additional file 2). Articles set aside for inclusion after screening abstracts were single screened at full text with $20 \%$ of articles double screened at full text to ensure consistency. All articles screened and excluded at full text were recorded, the methodology was coded and a brief outline of the content and the reason for exclusion is provided (Additional file 3). No articles included in the final synthesis were authored by the reviewers so there is no conflict of interest. None of the articles we screened were unobtainable. The systematic map guidelines were followed via the ROSES checklist (Additional File 4).

\section{Eligibility criteria}

\section{Eligible population}

The focus is on terrestrial mammals that are listed as vulnerable [21], endangered (EN) or critically endangered (CR) on the IUCN Red List. This is the global authoritative list of species in decline. Species included were further restricted to those for whom the IUCN threat assessment includes hunting and trapping as a key threat of which there are 172 species (listed in Additional file 1). The regional area of focus is Sub-Saharan Africa, as defined by the United Nations inclusive of 46 countries (Additional file 1). Many studies include multiple predator and prey species or use the catch-all expression bushmeat, if one species listed met the inclusion criteria the study was included.

\section{Eligible exposure}

The exposure of the populations outlined above to illegal hunting is the focus of this paper. While it is not necessary for a study to explicitly state the reason for the hunt, e.g. local subsistence hunting or transnational trafficking, the location of the kill must be included. The focus is on unregulated illegal hunting, hence studies on trophy hunting were excluded as this is a legal form of regulated hunting where quotas are set considering local population dynamics. Studies looking at mortality from zoonotic disease or other anthropogenic causes were also excluded.

\section{Eligible comparator(s)}

Various kinds of study designs are included in the map as shown in the results (Fig. 3). As the search progressed it became evident that including only studies that explicitly mention property rights arrangements would yield very few eligible studies despite shifting land use and ownership being an international cause of concern for wildlife. It was decided that studies would be included so long as the status of the land was mentioned, e.g. protected area, village land, rather than the explicit ownership arrangement. Various environmental and anthropogenic correlates were assessed between studies i.e. proximity of illegal hunting incidences to roads, water bodies, human settlement areas and anti-poaching ranger patrol bases.

\section{Eligible outcomes}

The evidence has to be geolocated. The locations of the kill sites were required to include primary data and not via referenced data from other studies. Data collected first hand can include records of carcass locations or signs of hunting, i.e. used shrapnel, snares, hunter arrest records or via hunter follows, interviews and/or surveys. Variation in the number of species consumed or sold is also an eligible outcome if the capture location(s) is included.

\section{Exclusion criteria}

Demographic studies containing data only on species abundance and distribution were excluded. Similarly, studies that only contain data on species behaviour in response to a perceived threat, e.g. monitoring flight 
initiation time were excluded. Studies that infer the level of illegal hunting by providing proxies, e.g. bushmeat price as an indicator of supply were excluded. All articles excluded at full text were recorded with a description of the focus of the article and the reason for exclusion (Additional file 3).

We excluded the following kinds of articles:

- Theoretical or modelling studies and purely qualitative research that does not include any quantitative data.

- Editorials and commentaries.

- Social commentaries that do not include any quantitative data.

- Literature reviews.

\section{Study validity assessment}

We did not conduct a study validity assessment on the results of our searches as the purpose of the searches was to cover a broad spectrum of methods. Articles were judged against the eligibility criteria outlined above.

\section{Data coding strategy}

Data extraction consisted of two stages carried out by three reviewers. Once articles were screened at the level of title/abstract, 206 articles were put aside to be reviewed at full text. At this stage the title, focus of the study and method used for data collection was recorded, alongside the reason why articles were excluded (Additional file 3). The methods used to collect data on illegal hunting were reviewed and grouped and codes were created (Additional file 5). Once this stage was complete and the 47 articles that met the inclusion criteria remained, we used a separate coding sheet (Additional file 6) to extract the following relevant information:

1. Bibliographic information: publication type, title, publication year, etc.

2. Study context: country, land tenure type, size of study area, number of sites, taxa.

3. Study design: method used for data collection, unit of analysis, sample size, length of data collection.

4. Outcomes: spatial variation in the level of hunting, stated conclusion/finding of study.

To ensure consistency the first $20 \%$ of articles was coded by two reviewers. It was necessary to consult the supplementary material in several cases and in four cases to directly contact the authors for information.

\section{Data mapping method}

Comparable points of information were extracted to categorise and compare, variables such as proximity to roads, water bodies, distance to human settlements and ranger patrol bases were recorded as were the countries and the list of species included in the study (Additional file 6). To gain an understanding on the different methods in use we created a key of methods in use (Additional file 5), these were grouped and visualised in a bar graph showing included and excluded studies. To show the geographic distribution of studies we grouped these via a choropleth map and the variety of taxa were visualised via a Sankey diagram. This enabled us to identify knowledge gaps. For example, there is a lack of research outside protected areas and geographically there is a lack of studies in central and west Africa.

\section{Results}

\section{Number and types of articles}

Figure 1 details the step-by-step results of the systematic mapping process. 12,645 articles were screened at title and abstract, 206 articles were read at full text of which 47 met the criteria.

1. What data are available on the spatial distribution of illegal hunting of terrestrial mammals in Sub-Saharan Africa in relation to environmental and anthropogenic correlates i.e. proximity to roads, water bodies, human settlement areas, different land tenure arrangements and anti-poaching ranger patrol bases?

a. What evidence exists on the impact of transport corridors on the spatial distribution of illegal hunting?

Studies that include proximity to transport networks in analysis span a diverse range of methods, including recording poaching signs e.g. carcasses, snares, cartridge shells; using tracking data to look at species mortalities; household dietary recall surveys and bushmeat market surveys. In Guinea higher carcass numbers were found in villages bordering a heavily trafficked road compared with rural villages in the same landscape [23]. In Nigeria and Cameroon, the price of bushmeat was found to increase closer to roads as it is thought that this increases access to distant markets [24]. A study in Ghana on the Pangolin trade found hunting frequency increased on busy roadside verges as this provides a point of direct sale to customers [25]. Increased hunting was found to increase in proximity to railway lines 
ROSES Flow Diagram for Systematic Maps. Version 1.0
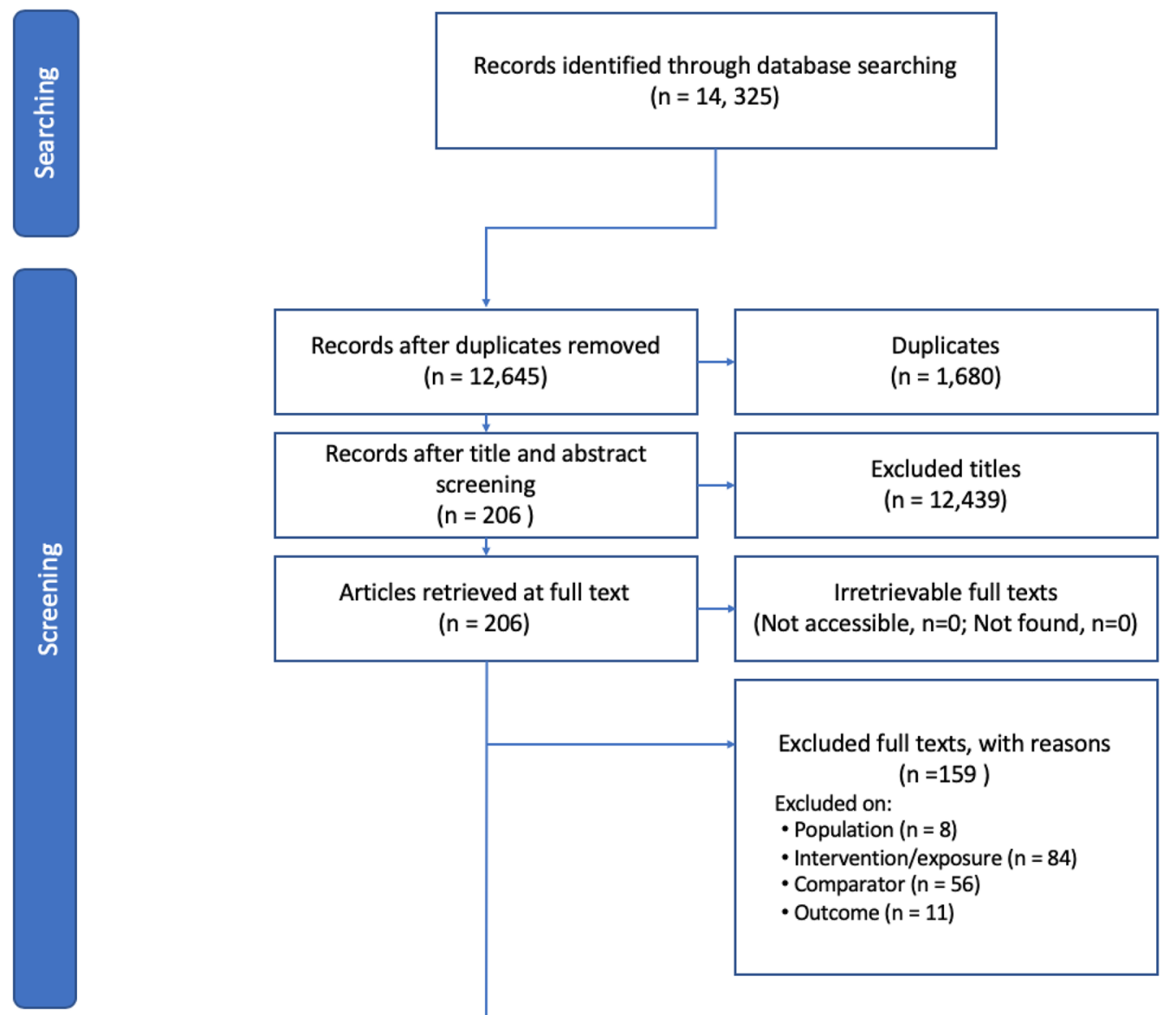

Articles retrieved at full text ( $n=206$ )

\section{Irretrievable full texts} (Not accessible, $n=0$; Not found, $n=0$ )

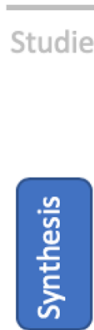

\begin{tabular}{|c|c|}
\hline Studies & $\begin{array}{l}\text { Articles included after full text } \\
\text { screening } \\
(n=47)\end{array}$ \\
\hline & $\begin{array}{l}\text { Studies included in the systematic } \\
\text { map database and narrative synthesis } \\
\qquad(n=47)\end{array}$ \\
\hline
\end{tabular}

Excluded full texts, with reasons ( $n=159$ )

Excluded on:

- Population $(n=8)$

- Intervention/exposure $(n=84)$

- Comparator $(n=56)$

- Outcome $(n=11)$

Articles

Fig. 1 Search, screening and full-text assessment flow chart [22]

as shown in a study on lions in Zimbabwe [26]. Another common impact of roads is accidental roadkill [27]. Proximity to transport networks was included in several analyses [23-30], exploring whether hunting pressure increases closer to transport networks globally would be amenable to systematic review (Fig. 2). b. What evidence exists on how seasonal variation and the spatial distribution of water bodies impact upon illegal hunting incidences?

Proximity to water resources is included in several analyses [26, 28, 31-36]. An analysis of 6 years of snare data in Tsavo National Park, Kenya found snare numbers were higher around 


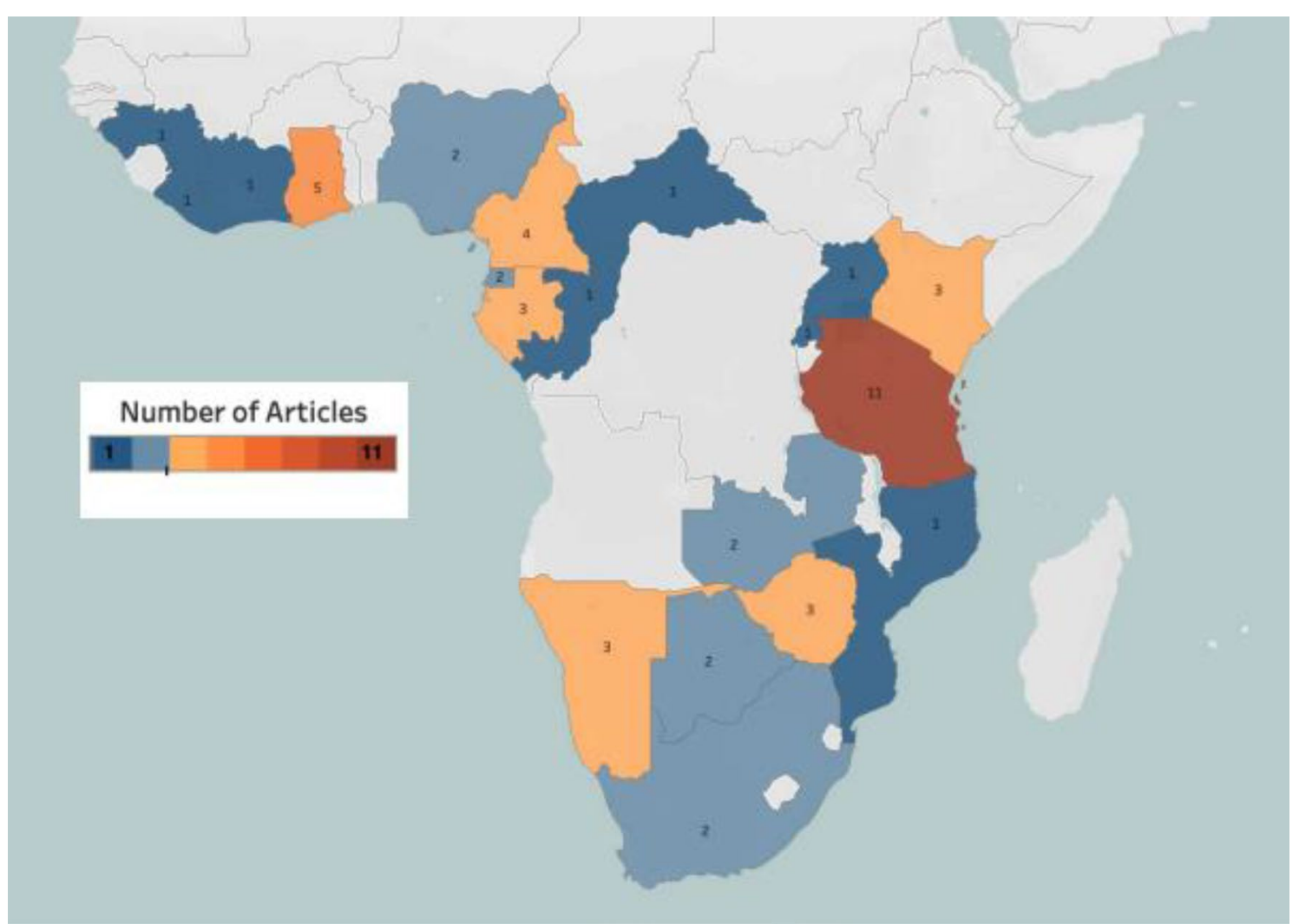

Fig. 2 Chloropleth map of inlcuded articles

water holes [28], the same was found in a study on lions in Zimbabwe [26] and for elephants in Tanzania [34]. Mammals tend to be easier to locate and hunt at water holes as they become stationary when drinking. The impact of seasonal variation on illegal hunting varies between studies, some report increases during the dry season and others during the wet season. Various reasons are given for the differences; the wet season offers an advantage to hunters as large areas of reserves and national parks cannot be accessed by roads which become muddy, washed out and often impassable, reducing access for patrol forces. Poachers can take advantage of the lack of enforcement in the wet season, although difficulty traversing the landscape will increase the unit of effort per catch. Another factor that makes it easier to hunt illegally in the wet season is the closing of tourism operations, i.e. legal trophy hunting operations, this enables poachers to move around with less risk of being caught [37]. In Gabon, hunting increased in the dry season during circumcision ceremonies as there is an increased demand for meat [38].
The rhythm of the agricultural season is mentioned as an influencing factor in several studies. During periods of low agricultural activity, hunting provides a replacement source of income, this was found in Cameroon [39], Ghana [40, 41] and Guinea [23]. During the wet season, hunters are largely occupied by other economic activities. In Guinea hunting varied between seasons for different species, e.g. hunting for ungulates and rodents increases in the dry season, while primates are more highly threatened in the mid-tolate rainy season when they are shot to prevent crop-raiding [23]. The majority of studies were conducted over a year or less, therefore seasonal variation could not be factored in. Seasonal variation is species and context-specific affected by many economic, social and cultural factors.

c. What evidence exists on how proximity to human settlement areas impact illegal hunting?

It is not possible to make an analysis on the impact of tenure as very few studies include more than one land tenure arrangement. Most studies in this map have been conducted in a single protected area looking at hunting incidences on 
a gradient from the border to the interior. Other studies analyse illegal hunting in a protected area at varying distances to another site, e.g. game reserve, customary land area, game management area. Logically, the majority of studies have focused on protected areas as this is where wildlife numbers are highest.

One study in Zimbabwe made a comparison between two areas of a conservancy: an area where adjacent land was settled by subsistence farmers after the fast-track land reform programme and another in an unsettled area in the north [42]. The resettled area was more strongly affected by illegal hunting. This halo of defaunation around a human settlement area has been identified in several studies [26, 32, 43, 44]. Increased hunting around a protected area was frequently cited, often referred to as an 'edge effect' [24, 25, 28, 29, 35-37, 45-54]. Different methods are used that find the same effect e.g. recording carcass and snare locations $[28,36$, $43-45,48,53,54]$, one household survey in Tanzania found wild meat consumption increased in villages closer to the park boundary [46] and several studies on bushmeat market surveys found the price decreased closer to protected areas indicating an increase in supply [24, 25]. Other studies using GPS or radio-tracking data to monitor mortalities found hunting was higher on the border of protected areas compared to the interior $[24,25]$. Illegal hunting likely increases on the border of protected areas as wildlife numbers increase by virtue of being next to a protected area.

d. What evidence exists to show how anti-poaching ranger patrol posts impact the spatial distribution of illegal hunting incidences?

Several studies analysed the impact of antipoaching ranger posts and patrol routes on illegal hunting incidences. One study, looking at hydrocarbon concessions in Central Africa, found, as expected, increased ranger patrols led to reduced poaching at a site [31]. However, in Tanzania mixed results were found: fewer elephant carcasses were discovered near several wildlife ranger posts, while an increase was detected at others-the variance was put down to disparities in resource allocation between posts [34]. To accurately analyse spatial variation in poaching incidences it is necessary to account for patrol effort. Catch Per Unit of Effort (CPUE) calculates the number of illegal activities identified per unit of patrol effort which is often used as a metric to assess deterrence efficacy; however, this can often be difficult to interpret [55].

An analysis of incidents at several sites where the SMART anti-poaching software is used found anti-poaching patrols had a greater impact in areas with open habitat, likely due to increased visibility [56]. Poaching threat maps that use illegal hunting data can generate understandings of how ranger patrol posts impact upon the spatial distribution of poaching incidences in the landscape. Poaching heat maps of this kind can be used to identify suitable locations where additional ranger posts could be established to reduce poaching. However, it is necessary to be careful with the use of poaching data as the primary focus of rangers is law enforcement, not monitoring [57]. Large portions of protected areas are unpatrolled due to limited resources, which makes inferences on the distribution of illegal activity challenging, at best, if not impossible in many locations. Rangers often cannot survey the landscape evenly as seasonal variation prevents access, i.e. during the wet season roads become washed out and it can be difficult to patrol in open savannah during hot periods. Patrol activity in most sites is badly understood due to a lack of recording and oversight. One recent study analysing spatio-temporal patrol presence in a large number of sites found patrols typically cover insufficient spatial scales to reduce illegal activity [56].

There have been several attempts to apply Artificial Intelligence (AI) and Machine Learning to patrol data to predict future illegal hunting incidents. The accuracy of predictions is based on biases contained within the collection of training data and should be treated cautiously [58]. Future primary studies regarding the impact of ranger posts on the distribution of illegal hunting incidences are recommended.

2. Which research methodologies have been used to collect quantitative data on illegal hunting and how comparable are these data?

The variety of methods used to collect quantitative data on illegal hunting is shown in Fig. 3-this shows all the methods that document levels of illegal hunting that were screened at full-text, however several of these do not collect spatially explicit information thus cannot be used to analyse spatial dynamics. The most common method identified in this review is abundance and distribution surveys which infer the severity of hunting by looking at fluctuations in population numbers. It is not possible to reliably attribute fluc- 


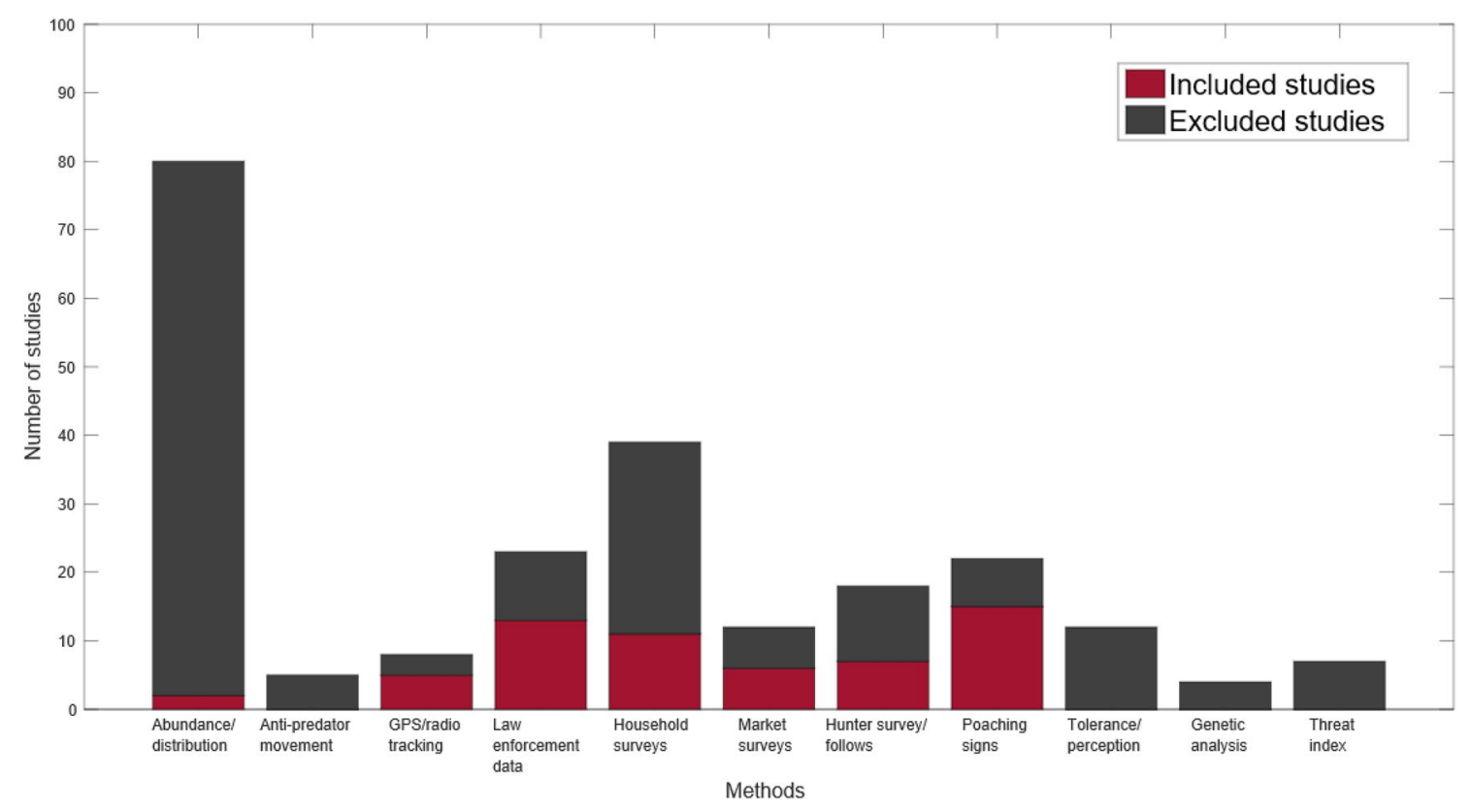

Fig. 3 Methods used to collect data on illegal hunting reviewed at full text

tuations in population numbers to illegal hunting as many variables impact survival rates. There are few longitudinal studies that include more than a year of data collection and no studies that survey the entire extent of a species range. Changes in the population at the site level do not reflect long-term population dynamics. As population numbers are a proxy indicator of hunting pressure and do not provide spatially explicit information, these have been excluded from the final map.

Several methods use animal movement data to assess the speed at which species flee when sensing an audible or visual threat; 'flight initiation' time is monitored visually or via radio or GPS tag to assess anti-predator behaviour $[59,60]$. These studies were excluded as they are not a direct measure of illegal hunting. Many studies use bushmeat household and market surveys, however, often the species hunted are not in the IUCN endangered categories and were excluded. Three study designs labelled 'tolerance and perception', 'genetic analysis' and 'threat index' appeared frequently during the title and abstract screening. 'Tolerance and perception' studies aim to gauge the level of local animosity toward wildlife through a variety of survey methods; the results are then used to ascertain the level of hunting risk in the landscape [7, 61-65]. As no quantified data are included, these were excluded. Studies using 'genetic analysis' can be divided into two: studies that look at landscape connectivity and resistance to gene flow caused by human settlement and infrastructure, and studies that genetically analyse seized teeth or bones to locate poaching hotspots [66-68]. It is possible to genetically identify kill locations only at very coarse geographic scales, so these were not included in the final synthesis. 'Threat index' studies take different forms, including modelling the optimal size of national park buffer zones to prevent hunting, modelling species survival rates after release and developing threat indices to establish which properties in the landscape cause greatest threat [69-72]. While these are relevant for assessing the threat of illegal hunting they were excluded as they do not provide hunting locations.

The majority of studies that met our inclusion criteria fall into two categories; they either use pre-existing law enforcement data collected on hunting incidences or the authors of the study collected data on hunting incidences via line transects, aerial counts or hunter follows recording capture locations. An advantage to pre-existing data collected by wildlife authorities is that these are often longitudinal and cover a larger area beyond the capacity of an individual study.

3. Is there a preference in the research body toward particular taxa and countries? Countries

Published data are only available for 19 of the 46 countries that constitute Sub-Saharan Africa, this is a small sample size considering the size of the region. There is a concentration of studies in Tanzania and 
a bias toward a single protected area-Serengeti National Park. Several of the largest countries in SubSaharan Africa contain no studies, i.e. the Democratic Republic of Congo, Sudan, and Chad. In West Africa, the majority of studies have been conducted in Ghana.

\section{Species included in the systematic map}

Some data collection methods are not conducive to recording taxa, e.g. analysis of snare data, as the species killed can be difficult to identify. Household surveys and illegal bushmeat market surveys often experience the same problem where consumers or sellers do not know the species being consumed. Figure 4 shows all species included in the final synthesis.

One hundred and seventy-two species in Sub-Saharan Africa are in the IUCN endangered categories listed as being at risk from hunting and trapping. However, spatially referenced quantitative data are only available for 23 of these species. The largest class of threatened taxa is primates who comprise 96 of the 172 listed species. This distribution is reflected in our review as spatially explicit data on hunting location is available for ten primate species-more species than in any other taxonomic group. The taxa covered are relatively representative of the distribution of species of conservation concern. There are some exceptions: no studies on bats met our inclusion criteria despite 14 bat species being listed in the IUCN endangered categories in Sub-Saharan Africa. Bats are relatively easy to hunt; hundreds can be trapped in a few hours as they cluster while roosting and netting are sold cheaply to protect crops. We expected spatially explicit data on the hunting of bats due to their connection with several vector-borne diseases, e.g. Rabies and Ebola. Hunting of certain species occurs for a variety of reasons; for cultural ceremonies, subsistence

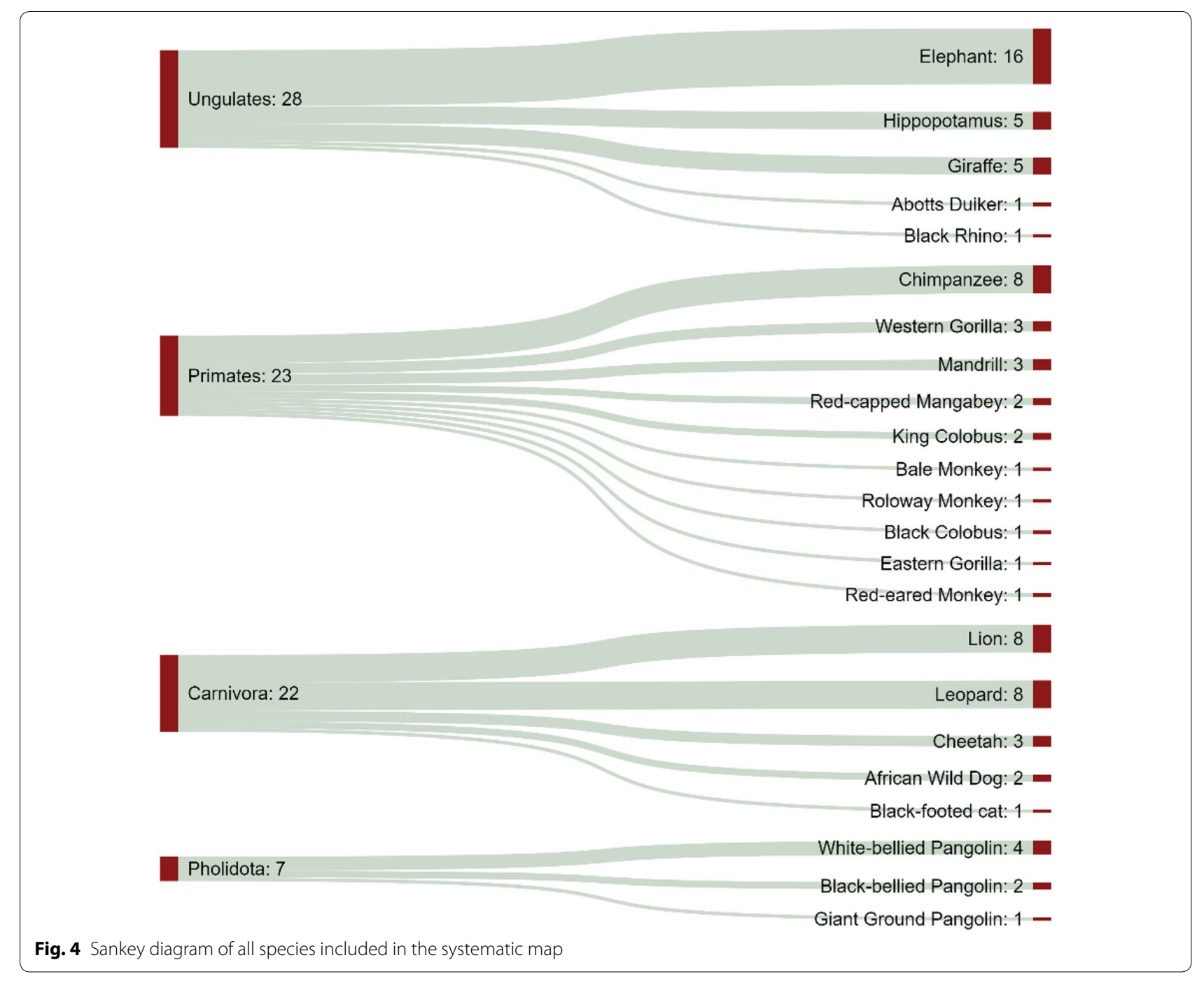


meat, ornaments, etc. and different parts of the animal are primarily sought, e.g. skin, teeth, bones, meat, organs. Specific cultural beliefs and taboos will also prevent some species being hunted over others.

\section{Limitations of the map \\ Limitations due to the search strategy}

One limitation in our search strategy was that we only consulted academic databases, we test ran the search terms on a number of organisational websites, but these did not yield any relevant results. Google Scholar was not consulted as we were advised by the University of Oxford Bodleian librarian that the peer reviewed articles it would provide would already be captured in the eight selected databases. Searches were only conducted in English as the majority of academic papers are published in English, the bias this introduces is likely to be small.

\section{Limitations due to bias in pool of articles found}

Our findings are restricted to Sub-Saharan Africa and to a small sample size. Spatial features included in this review may have a different effect in other locations and biomes. We only included articles on species of conservation concern which reduced the number of articles included. The absence of studies with qualitative data is a limitation as social and cultural factors that drive hunting are not considered. Sociological information is critical for understanding the context in which poaching occurs, but these variables are not easy to compare across diverse geographical locations.

\section{Conclusions}

\section{Implications for policy/management}

This systematic map categorised all the available evidence relating to the research questions. The intention is that policymakers find the map useful to gauge the extent of available evidence on illegal hunting of species of conservation concern. The key points of policy relevance are as follows:

- Few studies contain systematically collected data on poaching incidences; several applications have been developed to assist with data collection including Kobo Collect and the Spatial Monitoring and Reporting Tool (SMART). Funding these tools would enable the advancement of systematic data collection that would allow weights to be constructed in geospatial models to forecast future poaching incidents.
- Discerning what local spatial biases exist and including these in the design of anti-poaching patrol schedules would help to make best use of, often stretched, patrol resources.

- Seasonal fluctuations in illegal hunting varied between studies as seasonal employment opportunities for local people change. This shifting temporal factor should be considered in anti-poaching conservation programmes when planning annual patrol intensity.

- There is a research bias toward East Africa in the studies collected. It is recommended that conservation funding be directed toward collection of improved illegal hunting datasets in central and west Africa so as to gain a better understanding of illegal hunting dynamics in these regions.

\section{Implication for research}

This map identified several understudied subtopics which would benefit from primary research. The research gaps identified were as follows:

- On review of the evidence base it is clear that an analysis on the influence of tenure is not possible as there are too few comparative studies between adjacent land tenure areas. Future longitudinal research studies comparing hunting incidences in adjacent land tenure sites, where other variables remain similar would allow for an assessment of this relationship.

- The studies included in this review show discernible spatial patterns in illegal hunting incidences, however due to variation in methodology and study length it would not be possible to compare studies directly via meta-analysis [69-72]. However, a systematic review could assess the spatial trends in the evidence globally to establish what spatial patterns are consistent across biomes. This information could then be used to guide anti-poaching patrols and optimally position wildlife ranger posts which is particularly relevant as predictive modelling using AI and Machine Learning is advancing.

- Biased collection of biodiversity datasets is well documented [73] as is apparent in this map-research is encouraged in these understudied areas. Several countries have no spatially explicit data available e.g. Angola, Democratic Republic of Congo.

- Future research assessing the relationship between the size of buffer zones and levels of illegal hunting is recommended to establish whether buffer zones act as an important deterrent. 


\section{Supplementary information}

Supplementary information accompanies this paper at https://doi. org/10.1186/s13750-020-00195-8.

Additional file 1. Inclusion criteria: Countries in Sub-Saharan Africa defined by the United Nations; IUCN search criteria and the list of articles used for benchmarking search strings.

Additional file 2. Search terms, databases consulted, the number of retrieved articles and number of articles screened after duplicates removed.

Additional file 3. Exclusion sheet listing the titles of the articles screened, the method used to gather data on illegal hunting, the focus of the study and the reason for exclusion.

Additional file 4. ROSES Systematic map checklist.

Additional file 5. The key created for the methods used to monitor illegal hunting.

Additional file 6. Details of included studies: Title, country, species name, the research method used for data collection, the main finding of the article, the tenure of the land under investigation, the period of data collection and mention of the following factors: 1. anti-poaching ranger patrol bases, 2. Proximity to water, 3. Season and 4. Proximity to transport networks.

\section{Acknowledgements}

Thanks to the Natural Environment Research Council for funding training in the CEE synthesis process and for funding a placement at the University of Exeter where the protocol for this study was refined. Thanks to Dr. Ruth Garside and Professor Nicola Randall for supporting the placement. Many thanks to the information specialists at the Bodleian libraries for their valuable input on refining the search strings and search strategy, in particular, Oliver Bridle, librarian at the Bodleian Radcliffe Science Library.

\section{Authors' contributions}

ID conceived the study and developed the parameters of the search strategy and inclusion/exclusion criteria with input from $\mathrm{TH}, \mathrm{TW}$, and oversight from DM. All authors contributed to the manuscript, led by ID. The scoping of the search strategy was developed with assistance from Oliver Bridle and Alison Bethel. All authors read and approved the final manuscript.

\section{Funding}

ID was supported by a scholarship from the Wildlife Conservation Research Unit (WildCRU), Department of Zoology, Oxford. TH was supported by a Kadas Senior Research Fellowship at Worcester College, Oxford. DM was supported by a Senior Research Fellowship at Lady Margaret Hall, University of Oxford and Tiejun by the University of Twente.

\section{Availability of data and materials}

All data generated or analysed during this study are included in this published article [and its additional information files].

\section{Ethics approval and consent to participate}

Not applicable.

\section{Consent for publication}

Not applicable.

\section{Competing interests}

The authors declare that they have no competing interests.

\section{Author details}

${ }^{1}$ Wildlife Conservation Research Unit, Department of Zoology, University of Oxford, Recanati-Kaplan Centre, Tubney, Abingdon OX13 5QL, UK. ${ }^{2}$ Faculty of Geo-information Science and Earth Observation (ITC), University of Twente, P.O. Box 217, 7500 AE Enschede, The Netherlands.
Received: 15 November 2019 Accepted: 7 May 2020

Published online: 11 June 2020

\section{References}

1. McCallum ML. Vertebrate biodiversity losses point to a sixth mass extinction. Biodivers Conserv. 2015;24(10):2497-519. https://doi.org/10.1007/ s10531-015-0940-6.

2. Swanepoel LH, Lindsey P, Somers MJ, van Hoven W, Dalerum F, Pettorelli $\mathrm{N}$, Penteriani V. Extent and fragmentation of suitable leopard habitat in South Africa. Anim Conserv. 2013;16(1):41-50. https://doi.org/10.111 1/j.1469-1795.2012.00566.x.

3. Newmark WD, McNeally PB. Impact of habitat fragmentation on the spatial structure of the eastern arc forests in East Africa: implications for biodiversity conservation. Biodivers Conserv. 2018;27(6):1387-402. https ://doi.org/10.1007/s10531-018-1498-x.

4. Davies TE, Wilson S, Hazarika N, Chakrabarty J, Das D, Hodgson DJ, Zimmermann A. Effectiveness of intervention methods against crop-raiding elephants. Conserv Lett. 2011;4(5):346-54. https://doi.org/10.1111/j.1755263X.2011.00182.x.

5. Gunn J, Hawkins D, Barnes R, Mofulu F, Grant R, Norton G. The influence of lunar cycles on crop-raiding elephants; Evidence for risk avoidance. J Ecol. 2013:52:129-37. https://doi.org/10.1111/aje.12091.

6. Graham MD, Notter B, Adams WM, Lee PC, Ochieng TN. Patterns of cropraiding by elephants, loxodonta africana, in Laikipia, Kenya, and the management of human-elephant conflict. Syst Biodivers. 2010;8(4):435-45. https://doi.org/10.1080/14772000.2010.533716.

7. Gusset M, Swarner MJ, Mponwane L, Keletile K, McNutt JW. Humanwildlife conflict in Northern Botswana: livestock predation by endangered african Wild Dog Lycaon Pictus and other carnivores. Oryx. 2009;43(01):67-72. https://doi.org/10.1017/s0030605308990475.

8. Vanak AT, Fortin D, Thaker M, Ogden M, Owen C, Greatwood S, Slotow R. Moving to stay in place: behavioral mechanisms for coexistence of African large carnivores. Ecology. 2013:94:2619-31.

9. Thorn M, Green M, Dalerum F, Bateman PW, Scott DM. What drives human-carnivore conflict in the North West Province of South Africa? Biol Conserv. 2012;150(1):23-32. https://doi.org/10.1016/j.bioco n.2012.02.017.

10. van Velden J, Wilson K, Biggs D. The Evidence for the bushmeat crisis in African Savannas: a systematic quantitative literature review. Biol Conserv. 2018;221:345-56. https://doi.org/10.1016/j.biocon.2018.03.022.

11. Rutten M. Selling wealth to buy poverty: the process of the individualization of landownership among the Maasai Pastoralists of Kajiado District, Kenya, 1890-199. 1992: Breitenbach. 502. https://hdl.handl e.net/2066/113060.

12. Mwangi E, Ostrom E. Top-down solutions looking up. 2009. p. 34-45. https://doi.org/10.3200/ENVT.51.1.34-45.

13. Arezki $R$, Deininger $K$, Selod $H$. What drives the global land rush? In: International monetary fund. 2011. https://papers.ssrn.com/sol3/paper s.cfm?abstract_id=1952493.

14. Moreda T. Large-scale land acquisitions, state authority and indigenous local communities: insights from Ethiopia. Third World Q. 2016;38(3):698_ 716. https://doi.org/10.1080/01436597.2016.1191941.

15. Ewelukwa Ofodile U. Managing foreign investment in agricultural land in Africa: the role of bilateral investment treaties and international investment contracts. Law Dev Rev. 2014. https:/doi.org/10.1515/ Idr-2014-0010.

16. Ashukem J-CN. A rights-based approach to foreign agro-investment in Cameroon: enhancing the protection of local communities' rights. J Afr Law. 2019;63(2):163-91. https://doi.org/10.1017/s0021855319000196.

17. Kumagai J. This Ai Hunts Poachers. IEEE Spectrum 2018. 2020.

18. Fang F, Tambe M, Dilkina B, Plumptre A. Artificial intelligence and conservation. Cambridge: Cambridge University Press; 2019.

19. Hofer H, Campbell K, East M, Huish S. Modeling the spatial distribution of the economic costs and benefits of illegal game meat hunting in the Serengeti. Nat Resour Model. 2000. https://doi. org/10.1111/j.1939-7445.2000.tb00031.x. 
20. Duporge I, Hodgetts T, Brett M. What spatially explicit quantitative evidence exists that shows the effect of land tenure on illegal hunting of endangered terrestrial mammals in Sub-Saharan Africa? A systematic map protocol. Environ Evid. 2018. https://doi.org/10.1186/s1375 0-018-0139-x

21. Weise FJ, Lemeris JR Jr, Munro SJ, Bowden A, Venter C, van Vuuren M, van Vuuren RJ. Cheetahs (Acinonyx jubatus) running the gauntlet: an evaluation of translocations into free-range environments in Namibia. PeerJ. 2015;3:e1346. https://doi.org/10.7717/peerj.1346.

22. Haddaway NR, Macura B, Whaley P, Pullin AS. Roses flow diagram for systematic maps. Version 1.0. 2017

23. Brugiere D, Magassouba B. Pattern and sustainability of the bushmeat trade in the Haut Niger National Park, Republic of Guinea. Afr J Ecol. 2009;44:630-9. https://doi.org/10.1111/j.1365-2028.2008.01013.x.

24. Macdonald DW, Johnson PJ, Albrechtsen L, Seymour S, Dupain J, Hall A, Fa JE. Bushmeat trade in the Cross-Sanaga Rivers Region: evidence for the importance of protected areas. Biol Conserv. 2012;147(1):107-14.

25. Boakye MK, Kotze A, Dalton DL, Jansen R. Unravelling the pangolin bushmeat commodity chain and the extent of trade in Ghana. Hum Ecol. 2016;44(2):257-64. https://doi.org/10.1007/s10745-016-9813-1.

26. Loveridge AJ, Valeix M, Elliot NB, Macdonald DW. The landscape of anthropogenic mortality: how african lions respond to spatial variation in risk. J Appl Ecol. 2017;54(3):815-25.

27. Woodroffe R, Davies-Mostert H, Ginsberg J, Graf J, Leigh K, McCreery K, Robbins R, Mills G, Pole A, Rasmussen G, Somers M, Szykman M. Rates and causes of mortality in endangered African wild dogs Lycaon pictus: lessons for management and monitoring. Oryx. 2007;41(02):215-23. https ://doi.org/10.1017/s0030605307001809.

28. Wato YA, Wahungu GM, Okello MM. Correlates of wildlife snaring patterns in Tsavo West National Park, Kenya. Biol Conserv. 2006;132(4):500-9. https ://doi.org/10.1016/j.biocon.2006.05.010.

29. Wilfred P, Maccoll A. Local perspectives of factors influencing the extent of wildlife poaching for bushmeat in a game reserve, Western Tanzania. Int J Conserv Sci. 2015;6(1). http://www.ijcs.uaic.ro.

30. Wilfred P, MacColl A. The pattern of poaching signs in Ugalla Game Reserve, Western Tanzania. Afr J Ecol. 2014;52(4):543-51. https://doi. org/10.1111/aje.12161.

31. Hadrien V, Elie T, Angelique T, Lisa K, Alfonso A. Antipoaching standards in onshore hydrocarbon concessions drawn from a Central African case study. Conserv Biol. 2016;31(3):696-706. https://doi.org/10.1111/ cobi. 12854.

32. Lindsey PA, Romanach SS, Tambling CJ, Chartier K, Groom R. Ecological and financial impacts of illegal bushmeat trade in Zimbabwe. Oryx. 2011;45(1):96-111. https://doi.org/10.1017/50030605310000153.

33. Remis MJ. Preliminary assessment of the impacts of human activities on Gorillas Gorilla Gorilla Gorilla and other wildlife at Dzanga-Sangha Reserve, Central African Republic. Oryx. 2000;34(1):56-65. https://doi.org/ 10.1046/j.1365-3008.2000.00091.x.

34. Beale CM, Hauenstein S, Mduma S, Frederick H, Jones T, Bracebridge C, Maliti H, Kija H, Kohi EM. Spatial analysis of aerial survey data reveals correlates of elephant carcasses within a heavily poached ecosystem. Biol Conserv. 2018;218:258-67. https://doi.org/10.1016/j.biocon.2017.11.016.

35. Watson F, Becker MS, McRobb R, Kanyembo B. Spatial patterns of wiresnare poaching: implications for community conservation in buffer zones around National Parks. Biol Conserv. 2013;168:1-9. https://doi. org/10.1016/j.biocon.2013.09.003.

36. Lewis DM, Phiri A. Wildlife snaring — an indicator of community response to a community-based conservation project. Oryx. 1998;32(2):111-21. https://doi.org/10.1046/j.1365-3008.1998.d01-21.x.

37. Kyando M, Ikanda D, Røskaft E. Hotspot elephant-poaching areas in the Eastern Selous Game Reserve, Tanzania. Afr J Ecol. 2017;55(3):365-71. https://doi.org/10.1111/aje.12363.

38. Van Vliet N, Nasi R. Hunting for livelihood in Northeast Gabon: patterns, evolution, and sustainability. Ecol Soc. 2008;2(33). http://www.ecolo gyandsociety.org/vol13/iss2/art33/.

39. Matthews A, Matthews A. Survey of gorillas (gorilla gorilla gorilla) and chimpanzees (Pan Troglodytes Troglodytes) in Southwestern Cameroon Primates. 2004;45(1):15-24. https://doi.org/10.1007/s10329-003-0058-4.

40. Alexander JS, McNamara J, Rowcliffe JM, Oppong J, Milner-Gulland EJ. The role of bushmeat in a West African agricultural landscape. Oryx. 2015;49(4):643-51.
41. Schulte-Herbrüggen B, Rowcliffe JM, Homewood K, Kurpiers LA, Whitham C, Cowlishaw G. Wildlife depletion in a West African farm-forest mosaic and the implications for hunting across the landscape. Hum Ecol. 2013;41(6):795-806. https://doi.org/10.1007/s10745-013-9609-5.

42. Lindsey PA, Romañach SS, Matema S, Matema C, Mupamhadzi I, Muvengwi J. Dynamics and underlying causes of illegal bushmeat trade in Zimbabwe. Oryx. 2011;45(01):84-95. https://doi.org/10.1017/ s0030605310001274.

43. Fa J, Yuste G. Commercial bushmeat hunting in the Monte Mitra Forests, Equatorial Guinea: extent and impact. Anim Biodivers Conserv. 2001;24(1). https://core.ac.uk/reader/39042120.

44. Koerner S, Poulsen J, Blanchard E, Okouyi J, Clark C. Vertebrate community composition and diversity declines along a defaunation gradient radiating from rural villages in Gabon. J Appl Ecol. 2017. https://doi. org/10.1111/1365-2664.12798.

45. Joseph KB, Alexey V, William O. Analysis of human activities in and around protected areas (Pas): case of Kakum Conservation Area in Ghana. Int J Biodivers Conserv. 2014;6(7):541-54. https://doi. org/10.5897/ijbc2014.0691.

46. Mfunda I, Røskaft E. Bushmeat hunting in Serengeti, Tanzania: an important economic activity to local people. Int J Biodivers Conserv. 2010;2(9):263-72. https://doi.org/10.5897/IJBC.

47. Ceppi S, Nielsen M. A comparative study on bushmeat consumption patterns in Ten Tribes in Tanzania. Trop Conserv Sci. 2014;7(2):272-87. https://doi.org/10.1177/194008291400700208.

48. Imong I, Robbins MM, Mundry R, Bergl R, Kuhl HS. Distinguishing ecological constraints from human activity in species range fragmentation: the case of Cross River Gorillas. Anim Conserv. 2014;17(4):323-31. https://doi.org/10.1111/acv.12100.

49. Balme GA, Slotow R, Hunter LTB. Edge effects and the impact of nonprotected areas in carnivore conservation: leopards in the PhindaMkhuze Complex, South Africa. Anim Conserv. 2010;13(3):315-23. https://doi.org/10.1111/j.1469-1795.2009.00342.x.

50. Trinkel M, Fleischmann PH, Slotow R. Electrifying the fence or living with consequences? Problem animal control threatens the long-term viability of a free-ranging lion population. J Zool. 2017;301(1):41-50. https://doi.org/10.1111/jzo.12387.

51. Fischer A, Naiman LC, Lowassa A, Randall D, Rentsch D. Explanatory factors for household involvement in illegal bushmeat hunting around Serengeti, Tanzania. J Nat Conserv. 2014;22(6):491-6. https://doi. org/10.1016/j.jnc.2014.08.002.

52. Fa JE, Seymour S, Dupain J, Amin R, Albrechtsen L, Macdonald D. Getting to grips with the magnitude of exploitation: bushmeat in the Cross-Sanaga Rivers Region, Nigeria and Cameroon. Biol Conserv. 2006;129(4):497-510. https://doi.org/10.1016/j.biocon.2005.11.031.

53. Rogan MS, Tambling CJ, McNutt JW, Collins K, Golabek KA, Chase MJ, Lindsey PA. Illegal bushmeat hunters compete with predators and threaten wild herbivore populations in a global tourism hotspot, vol. 210. 2017.

54. Kahler JS, Roloff GJ, Gore ML. Poaching risks in community-based natural resource management. Conserv Biol. 2013;27(1):177-86. https ://doi.org/10.1111/j.1523-1739.2012.01960.x.

55. Stokes EJ. Improving effectiveness of protection efforts in tiger source sites: developing a framework for law enforcement monitoring using mist. Integr Zool. 2010;5(4):363-77. https://doi.org/10.111 1/j.1749-4877.2010.00223.x.

56. Dancer A. On the evaluation, monitoring and management of law enforcement patrols in protected areas. In: Centre for Biodiversity \& Environment Research. UCL \& Institute of Zoology, ZSL. 2019.

57. Gray M, Kalpers J. Ranger based monitoring in the Virunga-Bwindi Region of East-Central Africa: a simple data collection tool for park management. Biodivers Conserv. 2005;14(11):2723-41. https://doi. org/10.1007/s10531-005-8406-x.

58. Park N, Serra E, Snitch T, Subrahmanian VS. Ape: a data-driven, behavioral model-based anti-poaching engine. IEEE Trans Comput Soc Syst. 2015;2(2):15-37. https://doi.org/10.1109/tcss.2016.2517452.

59. Caro TM. Demography and behaviour of African mammals subject to exploitation. Biol Conserv. 1999;91(1):91-7. https://doi.org/10.1016/ s0006-3207(99)00033-6.

60. Marealle WN, Fossøøy F, Holmern T, Stokke BG, Røøskaft E. Does illegal hunting skew serengeti wildlife sex ratios?, vol. 16. 2010. 
61. Bauer $H$, de longh $H$, Sogbohossou E. Assessment and mitigation of human-lion conflict in West and Central Africa. Mammalia. 2010;74(4):363-7. https://doi.org/10.1515/mamm.2010.048.

62. Factors influencing perceptions of conflict and tolerance toward cheetahs on Namibian Farmlands.pdf.

63. Guerbois C, Dufour AB, Mtare G, Fritz H. Insights for integrated conservation from attitudes of people toward protected areas near Hwange National Park, Zimbabwe. Conserv Biol. 2013;27(4):844-55. https://doi. org/10.1111/cobi.12108.

64. Caro T, Elisa M, Gara J, Kadomo D, Martin A, Mushi D, Timbuka C. Integrating research with management: the case of Katavi National Park, Tanzania. Afr Zool. 2013;48(1):1-12.

65. McNutt JW, Stein AB, McNutt LB, Jordan NR. Living on the edge: characteristics of human-wild life conflict in a traditional livestock community in Botswana. Wildl Res. 2017:44(7):546-57. https://doi.org/10.1071/wr16160.

66. Genetic assignment of large seizures of elephant ivory reveals Africa's major poaching hotspots.pdf.

67. Ahlering MA, Eggert LS, Western D, Estes A, Munishi L, Fleischer R, Roberts M, Maldonado JE. Identifying source populations and genetic structure for Savannah elephants in human-dominated landscapes and protected areas in the Kenya-Tanzania Borderlands. PLoS ONE. 2012;7(12):9. https:// doi.org/10.1371/journal.pone.0052288.

68. Epps CW, Wasser SK, Keim JL, Mutayoba BM, Brashares JS. Quantifying past and present connectivity illuminates a rapidly changing landscape for the African Elephant. Mol Ecol. 2013;22(6):1574-88. https://doi. org/10.1111/mec. 12198 .
69. Page SK, Parker DM, Peinke DM, Davies-Mostert HT. Assessing the potential threat landscape of a proposed reintroduction site for carnivores. PLoS ONE. 2015;10(3):e0122782. https://doi.org/10.1371/journ al.pone.0122782.

70. Wittemyer G, Northrup JM, Blanc J, Douglas-Hamilton I, Omondi P, Burnham KP. Illegal killing for ivory drives global decline in African elephants. Proc Natl Acad Sci USA. 2014;111(36):13117-21. https://doi.org/10.1073/ pnas. 1403984111

71. Kiringe JW, Okello MM, Ekajul SW. Managers' perceptions of threats to the protected areas of Kenya: prioritization for effective management. Oryx. 2007;41(03):314-21. https://doi.org/10.1017/s0030605307000218.

72. Mugisha AR, Jacobson SK. Threat reduction assessment of conventional and community-based conservation approaches to managing protected areas in Uganda. Environ Conserv. 2004;31(3):233-41. https://doi. org/10.1017/s0376892904001432.

73. Hickisch R, Hodgetts T, Johnson PJ, Sillero-Zubiri C, Tockner K, Macdonald DW. Effects of publication bias on conservation planning. Conserv Biol. 2019;33(5):1151-63. https://doi.org/10.1111/cobi.13326.

\section{Publisher's Note}

Springer Nature remains neutral with regard to jurisdictional claims in published maps and institutional affiliations.
Ready to submit your research? Choose BMC and benefit from:

- fast, convenient online submission

- thorough peer review by experienced researchers in your field

- rapid publication on acceptance

- support for research data, including large and complex data types

- gold Open Access which fosters wider collaboration and increased citations

- maximum visibility for your research: over $100 \mathrm{M}$ website views per year

At BMC, research is always in progress.

Learn more biomedcentral.com/submissions 